\title{
An Analysis Innovation for Modern Service Industries' Ability requirement from Business Administration Talents
}

\author{
Che Chang Chang \\ School of Management \\ Fujian University of Technology \\ Fuzhou, Fujian, China \\ 1794298328@qq.com
}

\author{
Yi Chou Wang \\ Department of International Business Management \\ Tainan University of Technology \\ Tainan, Taiwan \\ yichou@hotmail.com
}

\begin{abstract}
Modern service industries have become an important engine for leading the world economic growth. In China, service industries have created lots of job opportunities for undergraduate students, especially for business administration majors. This study tries to find out what enterprises prefer when they request employees engaging in business management. Several factors were involved in dependent variables while conducting a survey. The analytic hierarchy process (AHP) was applied to compare the relative importance of different variables. After data analysis, suggestion for improving business majors' professional skills from time to time was made.
\end{abstract}

Keywords-Modern service industry; bueiness administration; talents; analytic hierarchy proescc (AHP)

\section{INTRODUCTION}

Numerous scholars have conduced massive analyses to investigate enterprises' needs for business management workers. Business majors possessing certain abilities or having cross-field expertise is regarded indispensible and important by enterprises in terms of corporate sustainable development. Business management talents not only should possess general knowledge about all service industries, but also should have professional skills and reliable personalities. Business management talents are critically important in the management team, in terms of the long-term development of enterprises. The present study took high- and mid- business managers in small- and medium enterprises as the participants to explore what nowadays enterprises' exactly need concerning the abilities of business management employees. Analytic hierarchy process (AHP) was adopted as a data analysis instrument.

\section{LITERATURE REVIEW}

A. Business and management talents' capacity requirements in modern servic industries

The report of Communist Party's $15^{\text {th }}$ meeting initially proposed the term of "modern service industries" in September, 1997. The Fifth plenary session of the official presentation pointed out the goal of "development of modern service industries, restructuring, and transformation of traditional service industries" in October 15, 2000. Ministry of Science and Technology issued document No. 70: "Technological development of modern service industries", in which "Ten-two-five project" indicated that modern service industries are developed based on Internet technology, new commercial mode, service types and management methods. What the paper emphasizes not only new service industries, but also transformation and promotion of traditional service industries by means of modern technology.

In the "The important role in the economic development of modern service industries and research of enterprises' demands", Wu Xiaoping classified modern service industries into the following categories [1]: (a) basic services: communication services and information services; (b) production and market services: finance, logistics, wholesale, e-commerce, agricultural support services, and consulting; (c) individual consumer services: education, health care, accommodation, entertainment, tourism, real estate, retail and so on; (d) public service: public management services, basic education, public health, medical and welfare services, and so on.

In "Review of the modern service industry theory", Lee Kum Shu, Xuyao Yao classified modern service industries into the following categories based on three different standards [2]: (a) in accordance with the regulations of WTO concerning service trade and service industries, the nine categories are respectively: financial services, communication or telecommunication services, business services, educational services, health and social services, construction and related engineering services, tourism, entertainment, cultural and sports services, and environmental services. (b) Official classification of industries, referring to new clauses in the United Nations International Standard in 2002, the definition of modern service industries involve real estate, information transmission, computer services, software industries, financial industries, education, culture, sports and recreation, water conservancy, environment and public facilities management industries, health, social security and social welfare sectors, and international organizations. (c) Chinese scholars classify 
modern service industries into two categories: one is the traditional service industries transformed through new technology and new methods and result in new service types, such as modern financial industries. The other is resulted from direct information industries and the development of information technology services, such as computer software and services, and mobile telecommunication services.

Modern service industries, compared with traditional services, are the service industries involving high-technology and high-culture in order to meet the needs of modern people and urban development. Modern service industry is accompanied by the development of information technology and knowledge economy. Only by mastering expertise of modern service industries can one keep up with the development of modern service industries. Besides, while having strong and professional skills, one should also possess practical abilities and innovative abilities.

Cao Weizhong, and Zhang Yingying [3] thought that business majors should have following abilities: (1) good political consciousness, good working ethics, hard-working spirit, team-work spirit, interpersonal communication and coordination capability, innovation and research capacity; (2) solid expertise; (3) superior sense of service and adroit operation skills; and (4) continuous innovation and adaptability. Other scholars put forward a higher level of capability, such as professional knowledge, familiarity with the rules of the industries, a global vision, and innovation.

\section{B. Categories and content of business management talents' abilities}

1) Basic knowledge about service industries. Possessing basic knowledge is very important, business management talents must understand and master relevant information which is useful for future studies and careers. The present study suggests that when engaging in modern service industries, one should possess basic knowledge involving knowledge about the industries, general management knowledge, and basic knowledge about the position.

2) Personality. Personality refers to the psychological factors which can cause a person to take the initiative to do something, and have certain psychological responses while encountering different situations. The present study classifies personality traits into three categories: professionalism, counter-frustration ability, and hard-working spirit.

3) For different fields of workers, being professional is a common requirement in all industries. Being professional is an indispensible quality for students because this quality is essential for developing a harmonious and economically prosperous society. Being professional is also an important factor for enterprises to determine whether the candidate has potential to be trained to be a superior employee and bring great benefits to the company. Being professional it is also the foundation for a worker to reach success in future career. Taibao [4] illustrates professionalism by defining that professionalism means an individual can assume his job responsibly, observe working ethics, be loyal to work, dedicate with diligence, concentrate on learning, and work selflessly.

4) On the Education of Psychological Quality, development and training to fight against frustration is important. In recent years, college campus violence and indulgence problems arise now and then. It means students' ability to tolerate frustration need to be improved. The socalled counter-frustration ability means that when an individual faces setbacks, they can actively and autonomously get out of troubles and make themselves free from mental and behavioral disorders. Counter-frustration ability comprising tolerance of frustration and overcoming of frustration.

\section{Service quality}

Expertise means that under the guidance of experts and scholars and through learning and training, an individual can have certain skills and thinking abilities. When working in modern service industries, one must fully possess professional knowledge, master all kinds of essential skills, and comprehensively keep learning in order to have better knowledge and skills in terms of enterprise development. Services expertise includes job skills, business management skills, customer relationships handling skills, and product planning skills.

1) Job skills mean the knowledge, skills, and experiences that a worker should possess.

2) Business management means activities of production, operation, investment, service, labor force, and finance which, in accordance with the company's operation purposes, are effective administration of regulations, control and coordination.

3) Customer relationship refers to the relationship among sellers, suppliers and buyers, and consumers. Customer relationship must be two-way communication and mutual understanding. The organization should handle the customer relationship by fully and accurately understanding customers' needs. Managing a good customer relationship depends on effective communication and coordination of all management departments.

4) Product planning means the activities and proposals of product development, marketing, and abolishment. Product planning is also known as merchandise planning, which is generally divided into two categories: one is plans of products research and development aimed at investigating demands of diverse markets and form an integrated line to develop and research new products in order to explore new markets and enhance sales revenues. The other type is plans of products marketing, which refers to exploring channels to sell products, marketing products continuously, and maintaining an ideal price of products. Generally speaking, it means how to sell products successfully and create new brand images.

\section{Ccertificates}

Business management graduates should possess job-related certificates such as certificates of English proficiency, certificate of computer skills and certificates of different 
professional fields (i.e., certificates of accountants and human resources).

\section{E. Ggeneral ability about service industries}

In psychology, general ability means basic capability, which refers to the ability in dealing with various daily life activities. General ability about modern service industries consists of communication skills, team-work ability, analyzing and induction ability, innovation, and emotion management skills.

1) A philosopher once said: "Having no communication ability is like a boat on land, and will never reach the sea of life." Communicative competence is the most important communication skill. Good communication means being able to express one's ideas reasonably and effectively to makes others understand. Good communication comes from selfconfidence and mutual-understanding.

2) Team-work abilities require every member of the team should have team spirit. It means an individual should be able to collaborate and work with other team members, coordinate with each other, and help each other. Caoqi Fu compiled a "Questionnaire of college students' team-work and collaboration ability" [5]. After the analysis, he analyzed the results and classified college students' team-work and collaboration capabilities include two aspects: first, college students are able to tell right from wrong, think independently, critically and creatively; secondly, college students can think actively; be willing to exchange know-how and share happiness with others; and can confidently express their viewpoints. However, college students also have some weaknesses, such as utilitarianism, lack of team-work spirit, interpersonally autistic, lack of communication skills, apathy of participation in social activities, lack of participation awareness, alienation in cooperation, lack of team-work, naivety of self-positioning, and lack of responsibility.

3) The three elements of competitiveness in nowadays enterprises are respectively corporate core resources, corporate culture and innovation ability. Faced with an increasingly complex business environment, in order to be competitive constantly, one must be able to recognize the fact that the environment is ever-changing, accordingly make appropriate adjustments and allocate appropriate resources to cope with the ever-changing society. Only by doing this can make enterprises be able to adapt to ever-changing environment, help them have sustainably competitive advantages, and help them to be innovative. Li Yuan investigated college students' innovative abilities and the results showed that $15.2 \%$ of students reported having innovation; only $4 \%$ of students reported having little inventions [6]. The public believes that $78.5 \%$ of students are innovative. Li's research shows that innovative ability is important, but actually, there is still a wide gap between the fact and ideal expectation. In terms of innovation, an individual must be able to use professional knowledge and skills to create a good environment and atmosphere.
4) Emotion management was originally a psychological term. Emotion management is an individual's self-control of emotion. Daniel Goleman [7] puts forward "emotional intelligence" theory in his book. Emotional intelligence can be roughly summarized as five abilities: self-awareness, selfmanagement, self-motivation, empathy, and social skills. For university students who are at their turning point in their life, their world view, values, and outlook on life have been basically formed, but their psychological status is not yet mature. It is inevitable that they might react irrationally to something, which may bring harm to damage their life and study. It is necessary to strengthen college students' knowledge of psychological health, and improve their abilities of emotion recognition and management.

\section{RESEARCH METHODS}

\section{A. Analytic hierarchy process (AHP)}

AHP-based method segments problems into individual one and establish hierarchal relationship. Pairwise comparison of relative weight was conducted by ratio scale of $1,2, \ldots, 9$, by establishing comparison matrixes, calculating eigenvalues and vectors, getting the biggest vectors after the consistency test, and finally achieving the relative weights of the evaluation criteria [8].

\section{B. Operation method}

First, the researchers established a hierarchy according to research themes and objectives, and then calculated the weight among all variables. The steps were as follows:

1) Establish a pairwise compairson matrix.

2) Pairwise comparison of matrix.

3) Obtaining vectos and maximal eigenvalue.

4) Consistency test.

\section{Participants}

High-level managers in service industries were recruited as the participants in order to understand what abilities they expect the business management talents should have. According to their opinion, the characteristics that they regarded important were analyzed in order to calculate its relative weight. A total of 55 questionnaires were distributed, and 37 were valid. The age of the participants was between 31 to 49 years old with 7 to 10 years of working experiences. The participants' qualification meets the purpose of the present study. Their information was as follows:

TABLE I. BASIC INFORMATION OF THE PARTICIPANTS

\begin{tabular}{|c|c|}
\hline Category & Number of distribution \\
\hline Working Experience & $\begin{array}{c}1 \sim 3 \text { years }: 3 ; 3 \sim 5 \text { years: } 9 ; 5 \sim 7 \text { year: } 3 ; 7 \sim 9 \\
\text { years: } 8 ; \text { over } 10 \text { years:14 }\end{array}$ \\
\hline Age & $20 \sim 30: 9 ; 31 \sim 40: 15 ; 41 \sim 49: 13 ;$ over $50: 0$ \\
\hline Industry & Basic services: $8 ;$ Production or marketing \\
& services: $13 ;$ Personal consumption and \\
& services: 9; Public services: 7 \\
\hline Position & Top manager: $10 ;$ Mid-level managers: $21 ;$ \\
& Professional and technical managers: 6 \\
\hline
\end{tabular}




\section{Hierarchy of service indistries' needs for business management talents}

Based on AHP hierarchy, the expected abilities of business management staff are classified into three levels: the first level is the purpose (Goal); the second level is aspect (Aspects); the third level is the target or object (Objects / Criteria). The present study classified the abilities of business management staff into 5 categories and 18 types respectively: basic knowledge about service industries, personality, professional skills about service industries, and relevant certificates. The basic abilities about service industries are shown in Fig. 1:

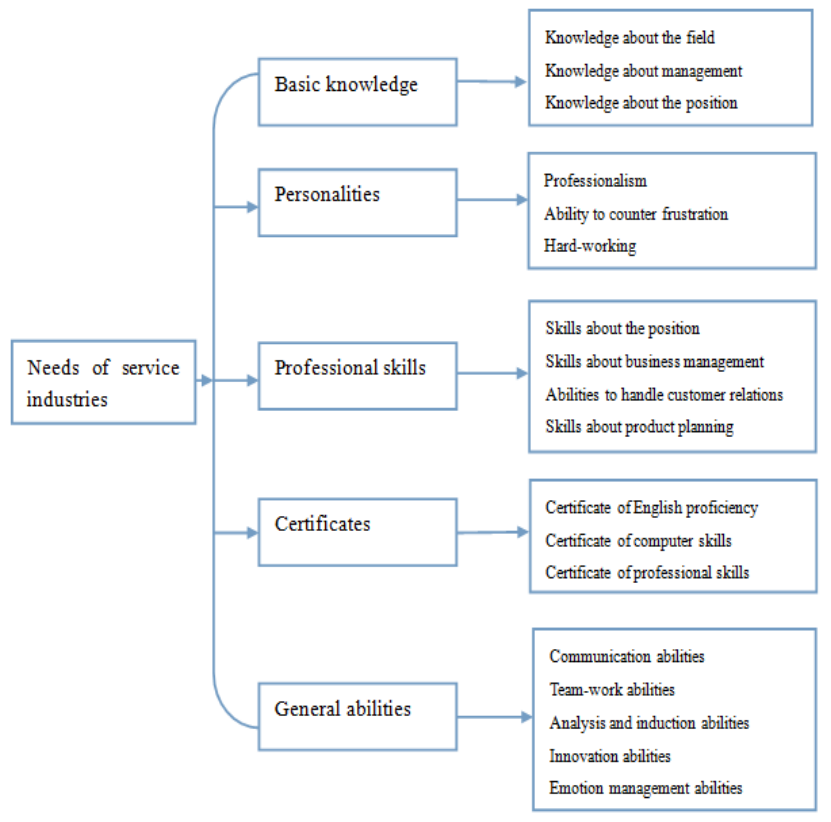

Fig. 1. Research framework

\section{E. Research tools: AHP questionnaire}

After item analysis, the consistency ratio is C.I. $\leq 0.1$ which means the items have strong internal consistency. If C.I.> 0.1, then the consistency is weak and the items are less reliable. Invalid questionnaires were excluded. Valid questionnaires were analyzed by geometry to get the ratio of weight, and then examined the overall consistency and the weight. On the selection of relative weights of the items in the questionnaire, Super Decisions software was used to analyze the relative weight of each selected item to calculate the priority and the relative weight of all factors in the hierarchy in order to obtain the weight ratio of the selected items.

\section{RESULTS OF WEIGHT ASSESSMENT OF THE DIMENSIONS}

Weight analysis of dimensions, criteria and items were analyzed by Super Decisions to get the relative weight of all variables and selected items:

\section{A. Results of weight assessment of the dimensions}

Geometry was used to get the weight assessment results of matrix and related facets (see TABLE II).
TABLE II. WEIGHT ASSESSMENT OF DIFFERENT DIMENSIONS

\begin{tabular}{|l|c|c|c|c|}
\hline \multicolumn{1}{|c|}{ Dimension } & Weight & Rank & CI & CR \\
\hline $\begin{array}{l}\text { 1. Basic knowledge } \\
\text { about service industries }\end{array}$ & 0.15434 & 3 & & \\
\cline { 1 - 3 } 2. Personality & 0.28051 & 2 & \multirow{2}{*}{0.00957} & 0.00085 \\
\cline { 1 - 3 } $\begin{array}{l}\text { 3.Professional skills } \\
\text { about service industries }\end{array}$ & 0.29691 & 1 & & \\
\cline { 1 - 3 } 4.Certificates & 0.12853 & 5 & & \\
\cline { 1 - 3 } $\begin{array}{l}\text { 5.General abilities about } \\
\text { service industries }\end{array}$ & 0.13971 & 4 & & \\
\hline
\end{tabular}

Based on Table 3, among the five dimensions, professional skills about service industries plays the most important role with the weight of 0.29691 (26.691\%); personality ranked the second $(28.051 \%)$; basic knowledge about service industries ranked the third $(15.434 \%)$; general ability ranked the fourth $(13.971 \%)$; and certificates ranked the fifth (12.853\%). Detailed information is as the above TABLE II, C. I. values were less than 0.1 . This result showed that what the service industries concerned about most was professional abilities $(29.691 \%)$, followed by personality $(28.051 \%)$. On the other hand, general ability is not so important $(13.971 \%)$; however, it does not mean this ability is unimportant but means that this is essentially a basic competence.

\section{B. Results of data analysis of the weight assessment among the dimensions}

Weight assessment among the dimensions can be divided into local weight and overall weight. The test results were as follows:

\section{1) Local weight assessment among the dimensions}

a) When analyzing the basic knowledge about service industries, the present study adopted geometry to get the matrix and related facets of weight. The results are presented in TABLE III:

TABLE III. WEIGHT ASSESSMENT OF BASIC KNOWLEDGE ABOUT SERVICE INDUSTRIES

\begin{tabular}{|l|c|c|c|c|}
\hline \multicolumn{1}{|c|}{ Dimension } & $\begin{array}{c}\text { Local } \\
\text { weight }\end{array}$ & $\begin{array}{c}\text { Local } \\
\text { ranking }\end{array}$ & CI & CR \\
\hline 11.Industry knowledge & 0.06286 & 1 & & \multirow{2}{*}{0.02805} \\
\cline { 1 - 3 } $\begin{array}{l}\text { 12. General } \\
\text { management knowledge }\end{array}$ & 0.03911 & 3 & & \\
\cline { 1 - 3 } $\begin{array}{l}\text { 13. Basic knowledge } \\
\text { about the position }\end{array}$ & 0.05236 & 2 & \\
\hline
\end{tabular}

The above table showed that professional knowledge about the field was valued most by enterprises, followed by basic knowledge about the position. Obviously, those who intend to assume the position of business management should work hard to learn relevant and professional knowledge about the industries in order to make themselves work well in their position. Learning by doing, listening, observation, questioning and asking for experts' help will be a good way to help a freshman get used to the task as soon as possible and learn well. 
b) The present study used geometry to analyze the variables of personality dimension to get the matrix and weight of related aspects. The results are presented in TABLE IV .

TABLE IV. WEIGHT ASSESSMENT OF PERSONALITY DIEMSNION

\begin{tabular}{|l|c|c|c|c|}
\hline \multicolumn{1}{|c|}{ Dimension } & $\begin{array}{c}\text { Local } \\
\text { weight }\end{array}$ & $\begin{array}{c}\text { Local } \\
\text { ranking }\end{array}$ & CI & CR \\
\cline { 1 - 3 } 21. Professionalism & 0.12325 & 1 & \multirow{2}{*}{0.0026} & 0.000004 \\
\cline { 1 - 3 } 22. Ability to counter & 0.07222 & 3 & 2 & \\
\hline frustration & 0.08504 & 23. Hard-working ability & \multicolumn{2}{l}{} \\
\hline
\end{tabular}

Note : $C I .<0.1, \mathrm{CR}<0.1$ meets consistency

As described above, personality is considered import by enterprises. The above table clearly indicated that professionalism and hard-working are what enterprises concern about. In other words, business management workers have to be hard-working and practical, and exactly administer what they plan to do.

c) The present study adopted geometry to get the matrix and related weight to evaluate the dimension of professional skills about service industries. The results are presented in TABLE V.

TABLE V. WEIGHT ASSESSMENT OF PROFESSIONAL SKILLS ABOUT SERVICE INDUSTRIES

\begin{tabular}{|l|c|c|c|c|}
\hline \multicolumn{1}{|c|}{ Dimension } & $\begin{array}{c}\text { Local } \\
\text { weight }\end{array}$ & $\begin{array}{c}\text { Local } \\
\text { ranking }\end{array}$ & CI & CR \\
\cline { 1 - 3 } 31. Job skills & 0.06278 & 3 & & \\
\cline { 1 - 3 } $\begin{array}{l}\text { 32. Business management } \\
\text { skills }\end{array}$ & 0.07207 & 2 & \multirow{2}{*}{0.00276} & 0.00031 \\
\cline { 1 - 3 } $\begin{array}{l}\text { 33. Customer relationship } \\
\text { handling skills }\end{array}$ & 0.10734 & 1 & 4 & \\
\cline { 1 - 3 } 34. Product planning & 0.05472 & 4 & & \\
\hline
\end{tabular}

According to the survey, the ability to manage customers is valued most by enterprises, followed by the business management skills. The reason is that having a good relationship with current customers can help enterprises create great benefits and significantly reduce the cost of establishing new relationship with new customers. On the other hand, job skills and product planning skills can be trained after workers entering the enterprises, and these two abilities are less important compared with other abilities.

d) The present study adopts geometry to get the matrix and related weight to evaluate the dimension of certificates about service industries. The results are presented in TABLE VI.

The majors of business management are generally enthusiastic to pass tests in order to acquire certificates. The results of the investigation also show that enterprises really value certificates very much. On the other hand, certificates of English proficiency and computer skills are not less cared about by enterprises but because they are considered to be a prerequisite for business majors. What enterprises concern about is employee's practical abilities, rather than whether they have certificates or how many certificates they have, because having certificates cannot guarantee the certificateholders exactly have superior abilities.

TABLE VI. WEIGHT ASSESSMENT OF CERTIFICATES DIMENSION

\begin{tabular}{|c|c|c|c|c|}
\hline Dimension & $\begin{array}{c}\text { Local } \\
\text { weight }\end{array}$ & $\begin{array}{c}\text { Local } \\
\text { ranking }\end{array}$ & CI & CR \\
\hline $\begin{array}{l}\text { 41. Certificates of English } \\
\text { proficiency }\end{array}$ & 0.01884 & 3 & \multirow{3}{*}{0.0143} & \multirow{3}{*}{0.02466} \\
\hline $\begin{array}{l}\text { 42. Certificates of } \\
\text { computer skills }\end{array}$ & 0.03507 & 2 & & \\
\hline $\begin{array}{l}\text { 43. Certificates of } \\
\text { professional skills }\end{array}$ & 0.07463 & 1 & & \\
\hline
\end{tabular}

e) The present study adopts geometry to get the matrix and related weight to evaluate the dimension of general abilities about service industries. The results are presented in TABLE VII.

TABLE VII. WEIGHT ASSESSMENT OF GENERAL ABILITY DIMENSION

\begin{tabular}{|c|c|c|c|c|}
\hline Dimension & $\begin{array}{c}\text { Local } \\
\text { weight }\end{array}$ & $\begin{array}{c}\text { Local } \\
\text { ranking }\end{array}$ & $\mathbf{C I}$ & $\mathbf{C R}$ \\
\hline 51.Communication skills & 0.02172 & 4 & \multirow{4}{*}{0.013337} & \multirow{4}{*}{0.01194} \\
\hline 52. Team work & 0.04377 & 1 & & \\
\hline $\begin{array}{l}\text { 53. Analyzing and } \\
\text { summarizing abilities }\end{array}$ & 0.03063 & 2 & & \\
\hline $\begin{array}{l}\text { 54. Learning and } \\
\text { innovation abilities }\end{array}$ & 0.02281 & 3 & & \\
\hline
\end{tabular}

According to the results, team-work ability is considered to be the most important by enterprises, followed by analyzing and summarizing abilities. It indicates that nowadays enterprises really concern about cooperation, while individually working alone has been insufficient to cope with the changes of the times. On the other hand, inductive analysis capabilities, innovation and communication abilities have been considered to be a must by enterprises.

\section{2) The overall weight assessment of all dimensions}

The relative importance of all dimensions is presented in Table 9. The top four important skills are respectively: professionalism, customer relationship handling skills, hardworking, and certificates of professional skills. All the above belong to aspects of personality, professional skills about service industries, personality, and certificates. The results can explain what service industries really need. Enterprises value their employees' personality most and then their professional skills and certificates. Among all aspects, the aspect of personality is ranked at 1,2 , and 5 respectively and it mans this feature is what enterprises really care about.

Furthermore, according to the ranking of the weight, the top four abilities are respectively: ability to counter frustration, business management skills, industry knowledge, and job skills, which are subordinate to services expertise excluding business management skills and job skills. Among the above four abilities, three out of four are external abilities. This can 
demonstrate that enterprises really concerned about professional skills and expertise, whereas innovation, communication skills, emotion management skills, and certificates of English proficiency are the least concerned by enterprises. Among the last four abilities, besides certificates of English proficiency, the other three abilities are just general abilities and are considered to be a prerequisite of students. Enterprises care more about their employees' competence than certificates.

TABLE VIII. WIGHT ASSESSMENT OF ALL ASPECTS

\begin{tabular}{|c|c|c|c|c|c|c|}
\hline Aspects & Local weight & Local ranking & Overall weight & Overall ranking & C.I. & C.R. \\
\hline 1. Basic industry knowledge & & & & & \multirow{4}{*}{0.02805} & \multirow{4}{*}{0.04836} \\
\hline 11. Relevant industry knowledge & 0.06286 & 1 & 0.03143 & 7 & & \\
\hline 12. General management knowledge & 0.03911 & 3 & 0.019557 & 12 & & \\
\hline 13. Basic position knowledge & 0.05236 & 2 & 0.026181 & 10 & & \\
\hline \multicolumn{5}{|l|}{ 2. Personality } & \multirow{4}{*}{0.00026} & \multirow{4}{*}{5.00004} \\
\hline 21.Professionalism & 0.12325 & 1 & 0.061623 & 1 & & \\
\hline 22.Counter-frustration ability & 0.07222 & 3 & 0.036111 & 5 & & \\
\hline 23.Hard-working ability & 0.08504 & 2 & 0.042518 & 3 & & \\
\hline \multicolumn{5}{|l|}{ 3. Services expertise } & \multirow{5}{*}{0.00276} & \multirow{5}{*}{60.00031} \\
\hline 31. Job skills & 0.06278 & 3 & 0.03139 & 8 & & \\
\hline 32. Business management skills & 0.07207 & 2 & 0.036033 & 6 & & \\
\hline 33. Customer relationship handling skills & 0.10734 & 1 & 0.053671 & 2 & & \\
\hline 34. Product planning skills & 0.05472 & 4 & 0.027361 & 9 & & \\
\hline \multicolumn{5}{|l|}{ 4. Job-related certificates } & \multirow{4}{*}{0.0143} & \multirow{4}{*}{0.02466} \\
\hline 41.Certificate of English proficiency & 0.01884 & 3 & 0.00942 & 18 & & \\
\hline 42. Certificates of computer skills & 0.03507 & 2 & 0.017533 & 13 & & \\
\hline 43. Certificates of professional skills & 0.07463 & 1 & 0.037313 & 4 & & \\
\hline \multicolumn{5}{|l|}{ 5. General ability } & \multirow{6}{*}{0.01337} & \multirow{6}{*}{0.01194} \\
\hline 51. Communication skills & 0.02172 & 4 & 0.010861 & 16 & & \\
\hline 52. Team-work & 0.04377 & 1 & 0.021886 & 11 & & \\
\hline 53. Analyzing and summarizing abilities & 0.03063 & 2 & 0.015316 & 14 & & \\
\hline 54.Learning and innovation abilities & 0.02281 & 3 & 0.011406 & 15 & & \\
\hline 55. Emotion management ability & 0.02077 & 5 & 0.010387 & 17 & & \\
\hline
\end{tabular}

\section{CONCLUSIONS AND SUGGESTIONS}

1) Enterprises concern about whether their employees can create a better future for their companies. Professional skill is regarded as the most important ability by enterprises, and that ability is what enterprises really expect from business management students. Furthermore, enterprises expect their employees can change the current status of enterprises, and expect their employees to have a forward-looking strategic thinking. Enterprises also expect their employees to be able to introduce or train potential workers in order help to enterprises have sustainable development.
2) Possessing general ability is a prerequisite of business management students. In addition to team-work ability, general ability is regarded as the least important by enterprises. It does not mean general abilities are unimportant, but rather necessary and a prerequisite. Enterprises expect their employees care more about their job in order to help enterprises develop well in the future.

3) Business management personnel must endeavor to pursue self-growth. Undoubtedly, professionalism, customer relationship handling skills, and hard-working ability are considered to be the top three important abilities by enterprises. All these depend on business management workers' continuous self-promotion. Only working hard on 
improving one's abilities can one be able to adapt to the everchanging society, understand the potential development of industries, and also train potential employees to gain more benefits for enterprises.

4) In addition to professional skills, industry-related knowledge, professionalism, skills, certificates, and teamwork ability are still what enterprises concern about. It means these abilities are necessary and indispensible. An excellent business management worker cannot be indecisive, unrealistic or unprofessional. Excellent workers must learn how to cooperate with others, learn from capable peers, and administer their plans. Only by doing so can help enterprises develop prosperously on and on.

5) Enterprises really concern about professionalism. Professionalism can mobilize, inspire and promote the development of the society. Professionalism means the worker should have high recognition and enthusiasm to their job positions, and assume their social responsibilities. Professionalism is a power from the bottom of the heart, rather than momentary excitement and enthusiasm. Whether enterprises can survive and develop continuously depends on professional and dedicated employees. More professional workers can assume more responsibilities than unprofessional workers, and create more interests for enterprises. As one saying goes, "what matters most is not the number of soldiers but the abilities of soldiers". Dedicated employees can have great contribution to the development of enterprises.

\section{References}

[1] Wu Xiaoping, The important role of the modern service industry talent demand trends in economic development research, Tianjin Vocational College of Business, 2012, 7

[2] Lee Kum Shu, Xu Yaoyao. Modern service theory, Jiangxi Normal University, 2013.

[3] Cao Weizhong, Zhang Yingying. Modern service application-oriented talents demands for professional capability survey and analysis, Tianjin Vocational College of Commerce, 2011.

[4] Wen Taibao. Founding of the essential qualities of students' employment, Tongling College, 2007.

[5] Caoqi Fu. Students' practical teamwork and training mode, Sichuan Cultural Industry Vocational College, 2008

[6] Li Yuan, Pan Shipping. Survey and developing mode of college students' self-learning and innovative ability, Changchun University of Technology, January 2013.

[7] Daniel Goleman, Emotional Intelligence, Shanghai Science and Technology Press, 1997.

[8] Saaty, T. L., The analytic hierarchy process, McGraw-Hill, New York, 1980. 